\title{
THE OCCURRENCE OF ARRHYTHMIAS AND HEART RATE VARIABILITY DURING DIVING IN RECREATIONAL DIVERS USING CONTINUOUS ELECTROCARDIOGRAPHIC HOLTER MONITORING
}

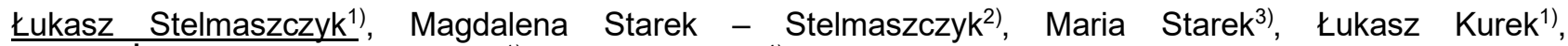 \\ Joanna Żuchlińska - Kwiatkowska ${ }^{1)}$, Michał Dębiński ${ }^{4)}$ \\ 1 Clinic of Gynecology, Oncological Gynecology and Obstetrics, Municipal Polyclinical Hospital, Olsztyn, Poland \\ ${ }^{2}$ Clinic of Cardiology and Internal Medicine with the Sub-department of Cardiac Intensive Care and Quick Diagnostics, Municipal Polyclinical Hospital, Olsztyn, \\ Poland \\ ${ }^{3}$ Warsaw Medical University, Faculty of Medicine and Dentistry, Poland \\ 4 Traumatology and Orthopedic Surgery and Rehabilitation Department, Mazovia Bródnowski Hospital, Warsaw
}

\section{ABSTRACT}

The aim of the research was to evaluate the occurrence of arrhythmias and heart rate variability during diving in recreational divers. Continuous electrocardiographic (ECG) Holter monitoring was conducted in a group of 50 divers (age $36,8 \pm 8,7$ ). The recorded data included the duration of the dive, including a period of 60 minutes before the dive and 60 minutes after the dive. Moreover, divers filled in a questionnaire that had been prepared for the purpose of the study and the psychological tests State-Trait Anxiety Inventory (STAI). The ECG recordings were synchronised with dive computers to correlate the ECG changes with diving events and analysed for the heart rate, arrhythmias and conduction disorders. The average heart rate was the highest ( $M=107.34$ beats/minute) before diving, and the lowest after diving ( $M=102.00$ beats/minute). Supraventricular arrhythmias were recorded in nineteen (38\%) of the participants of the study. The number of arrhythmias during diving $(M=14,45)$ is significantly higher than before $(M=9,93, p<0,01)$ and after dive $(M=6,02$, $p<0,05)$. All results were obtained from the continuous ECG Holter monitoring. It seems that using continuous ECG monitoring in conditions similar to diving (physical and psychological stress), brings more benefits than traditional, resting electrocardiogram.

Keywords: scuba diving, Holter ECG, electrocardiogram, heart rate, arrhythmias, blood pressure, medical examination.

\section{ARTICLE INFO}

PolHypRes 2019 Vol. 69 Issue 4 pp. 71 - 80

ISSN: 1734-7009 eISSN: 2084-0535

Original article

DOI: $10.2478 /$ phr-2019-0021

Pages: 10, figures: 0, tables: 2

page www of the periodical: www.phr.net.pl

Submission date: 28.04.2019 r.

Publisher

Polish Hyperbaric Medicine and Technology Society 


\section{INTRODUCTION}

The number of divers has been increasing in the recent years. As a result of growing availability, the group of those who dive is no longer limited to highly trained people who have undergone a thorough medical examination. More and more divers are elderly people, often affected by chronic diseases [1]. Changes in the recreational diver's profile are most clearly depicted by the fact that among divers who died underwater, the obesity rate is the same as in the total population of the United States and amounts to about $36.5 \%$ [2].

A lot of people do not realize, before taking up recreational diving, how demanding this sport is, both when it comes to required physical as well as psychological endurance. In Poland, in accordance with the law, the candidates for divers must undergo either a medical examination before diving or complete a medical declaration form and declare no contraindications to diving [3]. It might be assumed that among divers, like in the total population, there are people who are unaware of their real health condition and ones who provide inaccurate information in medical questionnaires.

Moreover, a number of diseases considered as contraindication to diving, may have no manifestations. That is why it is so important to undergo medical examinations. Among such diseases there are arrhythmias, which means inaccurate electrical activity of the heart. Noticeable arrhythmia symptoms may include: irregular heartbeat, dizziness, shortness of breath and even loss of consciousness. The basic heart monitoring test to diagnose arrhythmias is electroardiography (ECG). An ECG can be performed at rest or as a continuous Holter monitoring, performed non-stop over a few days. The aim of the research was to evaluate the occurrence of arrhythmias and heart rate variability in recreational divers during diving, an hour before and an hour after the dive.

\section{MATERIAL AND METHODS}

Having been granted the permission of the Bioethics Committee of Warsaw Medical University No. $\mathrm{KB} / 231 / 2013$, a prospective study in a group of 61 divers was conducted. The study included males aged 19-63 diving in dry suits. All of them did recreational diving without decompression. During diving they breathed with a nitrox mix with up to $32 \%$ oxygen. The analysis included 50 ECG records. 8 records were rejected because of poor quality, 2 because of lack of data concerning the dive profile, and 1 because of the medical history of the diver.

The mean age of the divers was 36.8 (SD 8.7), average diving experience in years 8.6 (SD 7.4), average number of hours underwater a year 136.3 (SD 153.4). Diving took place at an average depth of $13.6 \mathrm{~m}$ (SD 5.5), the mean visibility was $6 \mathrm{~m}(\mathrm{SD} 3 \mathrm{~m})$, and the mean water temperature was $8.3^{\circ} \mathrm{C}(\mathrm{SD} 3.9)$.

Characteristic of the group.

\begin{tabular}{|c|c|c|c|c|c|}
\hline & $\mathrm{N}$ & Min. & Max. & Avg. & SD \\
\hline Age & 50 & 19,00 & 62,00 & 36,7955 & 8,67656 \\
\hline $\begin{array}{l}\text { Diving experience } \\
\text { (age) }\end{array}$ & 50 & ,50 & 35,00 & 8,5568 & 7,39674 \\
\hline $\begin{array}{l}\text { number of hours } \\
\text { spent diving (per } \\
\text { year) }\end{array}$ & 50 & 10,00 & 800,00 & 136,3409 & 153,43978 \\
\hline Max. depth & 50 & 8 & 77 & 29,15 & 14,665 \\
\hline Ave. depth & 50 & 4 & 27 & 13,57 & 5,547 \\
\hline Dive time & 50 & 25,00 & 125,00 & 51,3864 & 19,61397 \\
\hline $\begin{array}{l}\text { Ave. water } \\
\text { temperature }\end{array}$ & 50 & 2,6 & 19,1 & 8,316 & 3,9232 \\
\hline $\begin{array}{l}\text { Min. water } \\
\text { temperature }\end{array}$ & 50 & 1,6 & 25,9 & 7,255 & 4,9326 \\
\hline
\end{tabular}

Dive time, depth, and general conditions of diving were not standardised. The divers' ECGs were constantly recorded with a tree-channel DMS 300-3A Holter. The recorded data included the duration of dive (mean time of dive $=51.4 \mathrm{~min}, \mathrm{SD}=19.6$ ), and a period of 60 minutes before the dive and 60 minutes after the dive. In order to obtain good quality records, the skin of the divers was prepared - cleaned, disinfected and shaved if necessary. 7 electrodes were attached in selected regions in line with the pattern recommended by the producer [4].

For the purpose of this study the recorder was placed in a waterproof casing made free-of-charge by GRALmarine, a diving equipment producer. The divers hung the casing across their shoulders when diving. There were no difficulties in diving with the device. Dive computers and the recorder were synchronised in order to analyse both the dive profile and potential underwater incidents as well as the ECG recordings. The latter were analysed with the Oxford program dedicated to the device. The heart rate variability and supraventricular and ventricular arrhythmias as well as conduction disorders were evaluated. Dive time was divided into two equal halves.

Before diving, every diver had their blood pressure checked; they also filled in the questionnaire that had been prepared for the purpose of the study. The subjects were asked about their chronic diseases, regularly taken medications, if they smoked, body weight and regular physical activity. Based on this information, the degree of training was evaluated. There were also questions about diving experience (in years) and number of hours spent diving per year. Moreover, the State-Trait 
Anxiety Inventory (STAI) X1 questionnaire which assessed anxiety levels before diving was filled in. The divers also assessed the level of difficulty of the dive they were to perform. After diving, the STAI X1 questionnaire, evaluating anxiety levels after diving, was again filled in. Thermal comfort during the dive (using 10 points scale) and the level of trait anxiety in the STAI 2 questionnaire were also assessed. The recorded data included the mean depth and maximum depth, duration of dive, visibility, water temperature and stressful underwater situations, defined as every unexpected event causing stress and/or required effort.

Statistical analysis was based on SAS 9. In order to analyse independent samples, i.e. to assess differences between groups depending on the diver's experience (related to their qualifications) the Mann-Whitney U test was applied. The Pearson correlation coefficient was used to verify the correlation of the heart rate and occurrence of arrhythmias during diving with the following variables: mean depth, mean water temperature, diving experience (in years), number of hours spent diving per year, and the level of qualifications. Similar correlations with regard to arrhythmias during diving were calculated. The Student's t-test for dependent samples was used to compare the mean heart rate in two halves of the dive. The nonparametric Friedman's test for dependent samples was used to assess the occurrence of arrhythmias and the heart rate before, during and after diving.

\section{RESULTS}

Mean heart rate before, during and after dive.

N $\begin{array}{ccccc}\text { Min. } & \text { Max. } & \text { Ave. } & \text { SD } & \text { Skewness }\end{array}$

\begin{tabular}{lllllll}
\hline Statistics & Statistics & Statistics & Statistics & Statistics & Statistics & $\begin{array}{l}\text { Standard } \\
\text { error }\end{array}$
\end{tabular} Statistics $\begin{aligned} & \text { Standard } \\
& \text { error }\end{aligned}$

\begin{tabular}{llllllllll}
\hline $\begin{array}{l}\text { Before } \\
\text { diving }\end{array}$ & 50 & 84,32 & 139,06 & 107,34 & 12,76 &, 510 &, 357 &, 344 &, 702 \\
\hline $\begin{array}{l}\text { During } \\
\text { diving }\end{array}$ & 50 & 80,15 & 140,06 & 105,15 & 13,30 &, 023 &, 357 &, 064 &, 702 \\
\hline $\begin{array}{l}\text { After } \\
\text { diving }\end{array}$ & 50 & 82,13 & 157,85 & 102,00 & 14,90 & 1,574 &, 357 & 3,577 &, 702 \\
\hline
\end{tabular}

\section{HEART RATE (HR)}

The analysis included the mean heart rate, which was compared for three periods - before, during and after diving. The heart rate in the analysed sample was the highest $(M=107.34)$ before diving, and the lowest $(M=102.00)$ after diving. There appeared a statistically significant difference of the mean heart rate between these periods $(\mathrm{p}<0.05)$. There was a significant negative correlation between the heart rate during diving and the experience of the diver at the level of $r=-0.31(p=0.05)-$ the more years of diving, the lower mean heart rate during diving. No correlation was shown between the heart rate during diving and the following variables: mean depth, mean water temperature, number of diving hours per year. Statistically significant differences were found between the mean heart rate in two halves of diving. In the second half it was higher $(M=109.16, S D=12.81)$ than the mean heart rate in the first half $(M=101.33, S D=14.88)$.

Mean HR in two halves of the dive.

\begin{tabular}{cll}
\hline & $\mathrm{N}$ & Ave. \\
\hline Mean HR in first half & 50 & 109,1626 \\
\hline Mean HR in second half & 50 & 101,3328 \\
\hline
\end{tabular}

\section{ARRHYTHMias}

Supraventricular arrhythmias were recorded in nineteen (38\%) of the participants of the study. In all cases, there were single supraventricular extrasystoles. No other supraventricular arrhythmias were observed. Ventricular arrhythmias were found in twelve divers (24\%), out of whom ten manifested single ventricular extrasystoles
(VE). In two divers a considerable number of VE were recorded - 203 in one diver and 1103 in the other.

Additionally, in one of the divers 3 episodes of ventricular bigeminy were observed, as well as one episode of non-sustained ventricular tachycardia with three contractions. On the basis of the conducted analyses, it was established that the number of arrhythmias during diving $(M=14.45)$ significantly differed from the number of arrhythmias before diving $(M=9.93, p<0.01)$ and after 
diving $(M=6.02, p<0.05)$.

In most cases these were single supraventricular extrasystoles. No significant differences were found between arrhythmias before and after diving. There were no conduction disorders in the studied group. No significance was determined in the analysis of the impact of such factors as the mean depth during diving, mean water temperature, diver's experience and number of diving hours per year on the occurrence of arrhythmias during diving.

No statistically significant correlations were found between STAI test results before and after diving (X1 and $\mathrm{X}-2$ ) and the heart rate in any of the analysed periods. No correlation was found between STAI test results and blood pressure values measured before and after diving. In one participant of the study hypertension was diagnosed according to the European Society of Cardiology (ESC) guidelines [5].

\section{DISCUSSION}

The heart rate (HR) is controlled by the autonomic nervous system comprised of the sympathetic division, which increases the HR and is activated during physical activity or strong emotions, and the parasympathetic division, whose activation results in a decrease in the HR [6].

Variability of the heart rate is a result of the activity of both divisions. However, underwater, the situation is more complicated, there are additional responses which do not occur on land, such as centralisation of the circulation caused by an increased pressure and a response to being submerged in water $[7,8,9]$. Definitely, an important factor which has an impact on the heart is the water-electrolyte balance [10].

Divers who use dry suits can suffer from overheating and can sweat before entering the water but also during diving, as it is a physically exhausting activity. Additionally, such divers consciously limit the liquids intake before diving to decrease diuresis. Our study showed that the mean underwater HR is lower than before diving and higher than after diving. Before the dive, the diver has to prepare and move his heavy equipment, that is make physical effort which undoubtedly increases the HR [11].

Moreover, especially less experienced divers get more tense before diving, which may lead to an increased HR. During diving, the HR is also affected by the physical effort related to the very activity of diving and emotions accompanying it [11]. On the other hand, the parasympathetic division is activated because the face is cooled [8], which results in bradycardia and contraction of peripheral arteries, which in turn leads to centralisation of the circulation and increased blood pressure [7,12-14].

In the current study, we observed that mean values of the HR were higher in the second half of the dive. In contrary, Bosco G. et al. noticed a lowered HR at the end of a dive [15]. The result of this study may be related to the sustained thermal comfort during diving, assessed in the questionnaire at 8 out of 10 . All divers had dry suits, neither of them reported hypothermia which could induce bradycardia [9].

It is possible there are other factors which have effect on the result, yet the most probable one in the case of our study is the dive profile - at the end of the dive the subjects usually had to come back to the place where they had started, so they had to make physical effort. Another factor that influences differences in the mean HR level is also the water-electrolyte balance, however, this was not analysed in the study as a variable. Lower HR values in more experienced divers result most probably from, among others, a better level of skills and motor coordination as well as less intense emotions during diving.

More experienced divers are better at dealing with difficult situations and solving problems underwater [16]. The lowest HR values were observed in the period directly after diving. Physical effort during this time was related solely to transporting the equipment to the shore or onto the boat. Then most divers rested after the dive and emotions most probably no longer affected their HR. In our group, two divers were found to have a significant number of ventricular arrhythmias, which required further diagnostics and possible treatment. What is important, these divers had not reported any symptoms before. This result is not statistically significant, yet it may have considerable clinical importance, especially in conditions such as staying underwater.

The latest 2017 Diving Alert Network (DAN) report on non-fatal diving accidents states that $1 \%$ of diving accidents were caused by arrhythmias, while $3 \%$ by loss of consciousness [2]. It is worth emphasising that detecting arrhythmias is not always possible and obvious, especially in patients who do not manifest any symptoms, because a disturbed HR does not have to occur continuously. The normal result of resting ECG does not exclude arrhythmia [17].

\section{Conclusions}

The more experienced the diver, the better adaptive changes such as lower mean heart rate during diving are observed.

In $6 \%$ of the tested divers a significant number of ventricular arrhythmias, a potentially life-threatening condition, were found. In the light of these results, it looks as if more detailed medical examination before diving is needed.

All data were obtained from continuous ECG Holter monitoring. It seems that continuous ECG monitoring in conditions similar to these during diving (physical and psychological stress) brings more benefits than the standard ECG conducted at rest, lasting just several dozen seconds. Continuous ECG Holter monitoring should be considered as a part of the examination required before being allowed to dive.

This was a pilot study, but analysing the obtained data, it seems that further research within a larger population is needed. 

charge.

We would like to thank GRALmarine for providing the special waterproof casing for the purpose of the study free of

\section{REFERENCES}

1. Lippmann J, McD Taylor D, Stevenson C, Williams J, Mitchell SJ. Diving with pre-existing medical conditions Diving Hyperb Med. 2017 Sep;47(3):180-190;

2. Buzzacott P. DAN Annual Diving Report 2017 Edition - A report on 2015 diving fatalities, injuries, and incidents. Durham, NC: Divers Alert Network, 2017;

3. Regulation of the Minister of Sport of 17 August 2006 on safety rules for diving;

4. http://pobieranie.oxford.com.pl/CardioScan_Holter/Instrukcje/Instr_obslugi_DMS300-3A_HDMI.pdf Stan na dzień 08.01.2020;

5. Williams B1, Mancia G, Spiering W, Rosei EA, et al. .ESC/ESH Guidelines for the management of arterial hypertension. Kardiol Pol. 2019;77(2):71159. doi: 10.5603/KP.2019.0018;

6. $\quad$ Ganong WF. Fizjologia; Ed. 1 Warszawa 2017 pp. $530-531$;

7. Kinoshita T, Nagata S, Baba R, Kohmoto T, Iwagaki S Cold-water face immersion per se elicits cardiac parasympathetic activity. Circ J, 2006; 70: 773-776;

8. Schuitema K, Holm B. The role of different facial areas in eliciting human diving bradycardia. Acta Physiol Scand, 1988; 132: 119-120. DOI: 10.1111/j.1748-1716.1988.tb08306.x;

9. Hayashi N, Ishihara M, Tanaka A, Osumi T, Yoshida T. Face immersion increases vagal activity as assessed by heart rate variability. Eur J Appl Physiol Occup Physiol. 1997;76(5):394-9. DOI:10.1007/s004210050267;

10. Gajewski P, Szczeklik A. Interna Szczeklika. ed.9, Publ. MP, Krakow 2018; 257;

11. Ganong WF. Physiology; Ed. 1 Warsaw 2017; 590;

12. Argacha JF1, Xhaët O, Gujic M, De Boeck G, Dreyfuss C, Lamotte M et al. Facial cooling and peripheral chemoreflex mechanisms in humans. Acta Physiol (Oxf), 2008; 194: 161-170. DOI: 10.1111/j.1748-1716.2008.01876.x;

13. Brown CM, Sanya EO, Hilz MJ. Effect of cold face stimulation on cerebral blood flow in humans. Brain Res Bull, 2003; 61: 81-86;

14. Tipton MJ1, Golden FS, Higenbottam C, Mekjavic IB, Eglin CM Temperature dependence of habituation of the initial responses to cold-water immersion. Eur J Appl Physiol Occup Physiol, 1998; 78: 253-257. DOI:10.1007/s004210050416;

15. Shilling CW, Wertes MF, Schandelmeier NR. The Underwater Handbook: A Guide to Physiology and Performance for the Engineer; Wyd. 1 New York 1976; 886;

16. Møller M. Standard ECG versus 24-hour Holter monitoring in the detection of ventricular arrhythmias. Clin Cardiol. 1981 Nov-Dec;4(6):322-4.

lek. med. Łukasz Stelmaszczyk

Klinika Ginekologii, Ginekologii Onkologicznej i Położnictwa

Miejski Szpital Zespolony w Olsztynie

e-mail: lukaszstel@o2.pl

tel.: 608-488-322 